\title{
Immunoagglutination Test Using Monoclonal Antibodies Coupled to Latex Particles to Identify The Streptococcus Pneumoniae Capsular Polysaccharides Serotype 1, 5, 6B, 14 And 19F In Quimi-Vio Vaccine
}

\author{
Elizabeth González Aznar, Abel Roscoe Fajardo Sánchez, Fidel Ramírez Bencomo, Ruben \\ Cabrera, Sandra Madariaga Zarza and Reinaldo Acevedo Grogues \\ Department of Biological Evaluation, Research Area, Finlay Vaccines Institute. .A .P. 16017, Havana Cod. 11600, Cuba
}

Received: July 13th ,2017; Accepted: July 23rd ,2017; Published: September 7th ,2017

${ }^{*}$ Corresponding author: Dr. Elizabeth Gonzalez Aznar, Finlay Vaccines Institute, Ave 17 Esq 198, Siboney, Playa, Havana, Cuba, Tel: +53 7269711; Email: elygonzalez@finlay.edu.cu and Dr.Reinaldo Acevedo,Email:racevedo@finlay.edu.cu

\begin{abstract}
Aims: To identify the PsC 1,5,6B,14,19F present in the Quimi-Vio vaccine by Immunoagglutination technique using in house Latex Reagents.

Introduction: Two types of pneumococcal vaccines have been approved for use in humans. All use the capsular polysaccharide ( $\mathrm{PsC}$ ), as a vaccine antigen, conjugated or not. Quimi-Vio, the Cuban pneumococcal vaccine, is composed by seven PsC $(1,5,6 \mathrm{~B}, 14,18 \mathrm{C}, 19 \mathrm{~F}, 23 \mathrm{~F})$ all conjugated to Tetanus Toxoid. The identification of these PsCs in the vaccine formulation is a mandatory requirement for the final lots release.

Materials and methods: Latex reagents were obtained by passive adsorption of monoclonal antibodies (MAbs) against PsC of serotypes 1,5,6B,14 and $19 \mathrm{~F}$ to latex particles of $0.8 \mu \mathrm{m}$. Three concentrations of MAbs (100, 200 and $500 \mu \mathrm{g} / \mathrm{mL})$ were evaluated for coupling. To each coupling variant was determined the percent coupling, the performance and specificity. The best variant was used to identify the PsCs present in three batches of Quimi-Vio vaccine.
\end{abstract}

Results: The best variant of latex reagent was the one that employed the concentration of $200 \mu \mathrm{g} / \mathrm{mL}$ of MAb for coupling, presented $100 \%$ of coupling, a response of three crosses and a high specificity, for all serotypes. This variant was selected to carry out the identity test, where all latex reagents from each serotype identified the homologous PsC, in the context of Quimi-Vio and Prevenar 13V vaccine.

Conclusions: The immunoagglutination technique using in house latex reagents using MAb, permit to identify specifically each PsC in the multivalent formulation, so it can be used for the Quimi-Vio identity test, thus guaranteeing batch release and quality control.

Keywords: Immunoagglutination; Identity Assay; Pneumococcal Vaccines; Monoclonal Antibodie

\section{Introduction}

Streptococcus Pneumoniae (Spn) is an encapsulated gram-positive diplococcus, responsible for a broad spectrum of infections in children and adults, including invasive infections (meningitis, bacteremia and bacterial pneumonia) and non-invasive infections (otitis media, sinusitis and conjunctivitis). However, this bacterium is recognized above all as the main etiological agent of Community Acquired Pneumonia, which mainly affects children (infants and up to 2 years) and elderly. Spn infection causes approximately 14.5 million cases of invasive pneumococcal disease annually and 0.7 to 1 million deaths in children under five years of age, mostly from developing and underdeveloped countries. [1, 2]

Capsular polysaccharide (PsC) has been considered the most important virulence factor of the bacterium. To date, 94 different capsular serotypes based on polysaccharide composition have been identified. Precisely based on PsC, two types of vaccines are currently used for the prevention of Spn infections: polysaccharide vaccines (PV) and conjugated polysaccharide vaccines (PVc). Among PV, we can mention Pneumovax $囚 23$ valences, indicated mainly in adults at risk of disease and in adults over 55 years. Within the PVc, there are Synflorix $®$ and Prevenar@ 13V, of 10 and 13 valences respectively, to cite an example. With these vaccines, protection against 23 serotypes has been attained (out of the 94 identified), but do not prevent against all pneumococcal diseases. [3, 4]

Another considerable number of vaccines against Spn are in researchdevelopment stage or in clinical trial. That is the case of "Quimi-Vio", the Cuban pneumococcal vaccine composed by the PsC of the seven serotypes with the highest incidence and circulation in Cuba (1, 5, 6B, 14, 18C, 19F and 23F), all conjugated to the Tetanus Toxoid as a carrier protein. It is a vaccine developed at the Finlay Institute of Vaccines that is currently in phase II of the Clinical Trial. $[5,6]$

Prophylactic vaccines like Quimi-Vio have the peculiarity of being given to healthy people, especially children in their first year of life. This aspect, together with others structural complexity, make regulations established, with the aim of guaranteeing the efficacy and safety of vaccines, from the research-development stages to the final product release. These controls include (among many others) the identification of active ingredients present in vaccines as a mandatory requirement for final product release. $[7,8]$

Several techniques have been used for vaccine identity test, among which are the immunoassays, that are simple techniques, easy to carry, to interpret the results, and accessible to all. Immunoagglutination technique specifically using latex reagents is within immunoassays and have been very useful because they are the fastest and can be carried out anywhere without the need of can technology complexity. $[9,10,11]$ In the case of Quimi-Vio identity test, highly specific techniques would be needed to identify each PsC (of the seven present) in the multivalent formulation. 
Monoclonal antibodies (MAbs) have become a powerful analytical tool, which have ensured the identity and quantification of PsC in various multivalent polysaccharide vaccines against Salmonella Typhi [12], Nesisseria meningitidis [13] and Haemophilus influenzae [14]. The MAb Laboratory of the Finlay Vaccines Institute recently obtained MAbs against five of the seven PsC present in Quimi-Vio $(1,5,6 \mathrm{~B}, 14$, and 19F), whose characterization process showed a high specificity and high affinity constant, which suggests its possible use as an analytical tool for the identity of the Quimi-Vio vaccine. The characterization studies of these MAbs have shown a high specificity and high affinity constant, aspects that suggest their possible use as an analytical tool for the Quimi-Vio vaccine. [15]

The present work proposes the identification of PsC 1, 5, 6B, 14 and 19F in Quimi-Vio vaccine, by immunoalgutination technique using monoclonal antibodies obtained in Finlay Vaccines Institute, coupled to Latex particles.

\section{Materials and Methods}

\section{Materials}

Monoclonal Antibodies (MAbs) against PsC serotypes 1, 5, 6B, 14, and 19F, obtained at MAb Laboratory of the Finlay Vaccines Institute

Multilatex®: Latex particles of $0.8 \mu \mathrm{m}$ in diameter at $10 \%$, obtained from Biomaterials, Havana University,Cuba.

Coupling Buffer: Phosphate Buffered Saline (PBS), Na2HPO4 3, 2 mM KH2PO4 0, 5 mM, KCl 1, 3 mM, NaCl 135 mM, pH 7,4

Preservation Buffer: Bovine Serum Albumin (BSA, Sigma) at $0.2 \%+$ Tiomersal at $0.02 \%$

Capsular polysaccharides (PsC) from Spn serotypes 1, 5, 6B, 14, and 19F Lots 15.01 obtained at the development plant of the Finlay Vaccine Institute and prepared at concentration of $4.4 \mu \mathrm{g} / \mathrm{mL}$ except $6 \mathrm{~B}$ which was prepared at $8.8 \mu \mathrm{g} /$ mL.

Spn strains: Serotype 1 (722), 5 (2471), 6B (285), 14 (989) and 19F (297), donated by Bactericide Laboratory of the Finlay Vaccine Institute

\section{Vaccines}

Quimi-Vio: Heptavalent conjugated polysaccharide vaccine against Spn serotypes 1, 5, 6B, 14, 18C, 19F and 23F. Lots NEU.15.01, NEU.15.02 and NEU.16.02, obtained under GMP conditions at the production plant of the Finlay Vaccines Institute. Composition: $4.4 \mu \mathrm{g} / \mathrm{mL}$ of all PsC except $6 \mathrm{~B}$ at $8.8 \mu \mathrm{g} / \mathrm{mL}$.

Prevenar $^{\mathrm{TM}}$ 13V: Pfizer 13-valent pneumococcal conjugate vaccine, lot 926785.02. Composition: $4.4 \mu \mathrm{g} / \mathrm{mL}$ of all PsC except 6 B found at $8.8 \mu \mathrm{g} / \mathrm{mL}$.

\section{Methods}

\section{Preparation of latex agglutination reagents}

Latex reagents were obtained in house by passive adsorption of the MAbs against the PsC of Spn serotypes 1, 5, 6B, 14 and 19F to Multilatex®.

\section{A. Procedure}

Three concentrations of each MAb $(100,200$ and $500 \mu \mathrm{g} / \mathrm{ml})$ were evaluated for coupling. For each mL of MAb in coupling buffer, $100 \mu \mathrm{L}$ of Multilátex® was added to a final concentration of $1 \%$. The mixture was incubated $2 \mathrm{~h}$ at $37^{\circ} \mathrm{C}$ in rotational stirring at $20 \mathrm{rpm}$. The uncoupled MAb was removed by centrifugation at $1100 \mathrm{~g}$ for $10 \mathrm{~min}$. The protein concentration in the supernatant (SN) was determined to calculate the coupling percentage. The final precipitate was resuspended in preservation buffer and was called latex reagent (LR). The LR variants were preserved at $4^{\circ} \mathrm{C}$. This process was performed in triplicate.

\section{B. Determination of the coupling percentage}

The coupling percentage (CP) of the different MAbs to the latex particle was calculated using the following formula: $\mathrm{CP}=100-(\mathrm{Cf} / \mathrm{Ci} \times 100)$

Where $\mathrm{Cf}$ is the final concentration of protein determined in the SN obtained from the first centrifugation and Ci constitutes the initial concentration of each
MAb in each LR variant. The BCA ${ }^{\mathrm{TM}}$ Protein Assay Kit (Piece, USA) was used for protein determination according to the recommendations described by the manufacturer. Visual inspection was carried out to test if suspensions of Latex coupled with the MAbs remain smooth and white after the coupling. Additionally, auto-agglutination phenomenon were evaluated with saline solutions by observation with unaided eye using an indirect light source.

\section{Performance of Latex Reagent Variants}

The performance was carried out by agglutination test against the PsC.

Test Procedure: The LR were first tempered. To perform the test, a dark background agglutination card (one card per serotype) was used, where $25 \mu \mathrm{L}$ of each of the three LR variants was placed in each well. Subsequently $25 \mu \mathrm{L}$ of the homologous PsC (prepared at $4.4 \mu \mathrm{g} / \mathrm{mL}$ ) was added in each well where the LR was. Using a plastic applicator the mixture was homogenized and gently shaken by manual rotation of the card during three minutes. As a negative control the PBS was used.

Interpretation of results: As a positive result, the appearance of lumps was considered up to 3 minutes after the reaction was initiated, by visual control. The degrees of positivity were expressed in crosses: three crosses (+++): agglutination observation within $1 \mathrm{~min}$, two crosses (++) from 1 to 2 min and a cross (+) up to $3 \mathrm{~min}$ from the start of the test.

\section{Selection of the best variant of latex reagent.}

It was selected as the best LR variant for each serotype, the one that showed the highest $\mathrm{CP}$ and better performance $(+++)$.

\section{E. Specificity}

The specificity was determined for the best variant selected by agglutination test similar to that described in section $\mathrm{c}$. In this case it was evaluated against Spn Strains of the serotypes 1, 5,6B, 14 and $19 \mathrm{~F}$ and against their respective $\mathrm{PsC}$, using one card per LR. In each well, $25 \mu \mathrm{L}$ of LR was applied and then $25 \mu \mathrm{L}$ of each PsC or Spn strain (one serotype per well) was added. The mixture was homogenized and gently shaken by manual rotation of the card for three minutes. As negative control (well 6) was used PBS. The results were expressed as presence of reaction $(+)$ or absence of reaction $(-)$.

\section{F. Detection Limit}

The sensibility or detection limit was determined for the best variant selected by agglutination test similar to that described in section c. In this case it was evaluated against PsC of the serotypes 1, 5,6B, 14 and 19F using one card per LR. In each well, $25 \mu \mathrm{L}$ of LR was applied and then $25 \mu \mathrm{L}$ of each PsC at different concentration, from $1000 \mu \mathrm{g} / \mathrm{mL}$ to $1 \mathrm{ng} / \mathrm{mL}$. The mixture was homogenized and gently shaken by manual rotation of the card for three minutes. As negative control (well 6) was used PBS. The results were expressed as presence of reaction $(+)$ or absence of reaction $(-)$.

\section{Quimi-Vio vaccine Identity Test}

The procedure used to perform the identity test was very similar to that described in section II.2.1E. A card was used per LR, applying $25 \mu \mathrm{L}$ of the LR to be evaluated, in each of the six wells of the card. $25 \mu \mathrm{L}$ of the three batches of the Quimi-Vio vaccine was then applied to the first three wells (one batch per well). In the fourth well, $25 \mu \mathrm{L}$ of the Prevenar 13 vaccine was applied and the positive (PsC homologous) and negative (SSTF) controls were applied in the two remaining wells respectively. Using a plastic applicator, the mixture was homogenized and gently shaken by manual rotation of the card during three minutes. The procedure was repeated for each RL of the five serotypes. Results of the identity assay were expressed as presence of agglutination $(+)$ or absence of agglutination (-).

\section{Results and Discussion}

Long is the process of bringing a vaccine candidate to clinical trial, and even longer to get it approved and licensed to administer massively. This happens because a lot of time is spent in characterizing the product very well and ensuring the quality of the vaccine. [16] 
The characterization and quality control of vaccines, unlike other drugs, is very difficult due to the complex molecular composition of the antigens, their production processes, and their interaction with agents used during manufacture or present in the Final lot, such as preservatives and adjuvants. [16, 17]

Until recently, quality control of vaccines relied on the use of various test methods to ensure that the products were safe and potent. These methods were developed for vaccines whose safety and efficacy were supported by several years of data. However, as the technologies for vaccine production have developed, so have the analytical technologies. Additional requirements such as identity, stability, purity, antigen structure and consistency of production are now required to obtain regulatory approval. [16, 17]

Thus the Identity Test is established by the World Health Organization (WHO) and the National Regulatory Authorities (in Cuba the CECMED), as a mandatory requirement for the final release of a vaccine. An identity test is defined as a set of methods for identifying in a formulation the active ingredient (s) present and stated in the product specification. The identity test is performed not only on the final vaccine, but also on the products of consignments (raw materials) or Active Pharmaceutical Ingredients (APIs), which are involved in the development process of a vaccine. They should be as fast as possible, simple, sensitive and above all specific. Generally they are qualitative rather than quantitative methods. $[8,17,18]$

In the case of the Cuban vaccine against Spn “Quimi-Vio", the identity test aims to identify (qualitatively) in the context of multivalent formulation the seven PsCs present in it. In this work we present the Immunoalgutination assay as a method to carry out the identity test of this vaccine, using the MAbs against five of the PsC present in the vaccine $(1,5,6 \mathrm{~B}, 14$, and 19F), coupled to latex particles. This is why the first step was to obtain the LR.

\section{Preparation and selection of latex agglutination reagents}

The LR for the immunoagglutination were obtained by passive adsorption of the MAbs against the PsC serotypes 1, 5,6B, 14 and 19F of Spn, to the particles Multilátex®. Three RL variants were performed based on the use of three concentrations of each MAb for coupling (Figure 1).

As can be seen in Figure 1, at the concentrations of $100 \mu \mathrm{g} / \mathrm{ml}$ and $200 \mu \mathrm{g} /$ $\mathrm{ml}$ of MAb used for coupling, all LRs reached $100 \%$ coupling. These results are in agreement with several authors who suggest that for $1 \mathrm{~mL}$ of PL of $0.8 \mu \mathrm{m}$, at $1 \%$, the theoretical IgG concentration necessary to saturate the surface area is estimated at $180 \mu \mathrm{g} / \mathrm{ml}$. However, the amount of antibody (Ab) able to cover the entire surface of the latex particles, depends not only on the diameter of the PL and the size of the molecule to be coupled, it also depends on the conditions of $\mathrm{pH}$, temperature, ionic strength and the hydrophobicity of Ab. $[11,19,20]$

The mechanism for passive adsorption is based primarily on hydrophobic (Vander Waals, London Type) attractions between the hydrophobic portions of the adsorbed ligands and the polymeric surface of the microspheres. This is the means of attachment for most hydrophobic ligands, including immunoglobulins. In the case of $\mathrm{Ab}$, the $\mathrm{Fc}$ portion of the protein is generally more hydrophobic

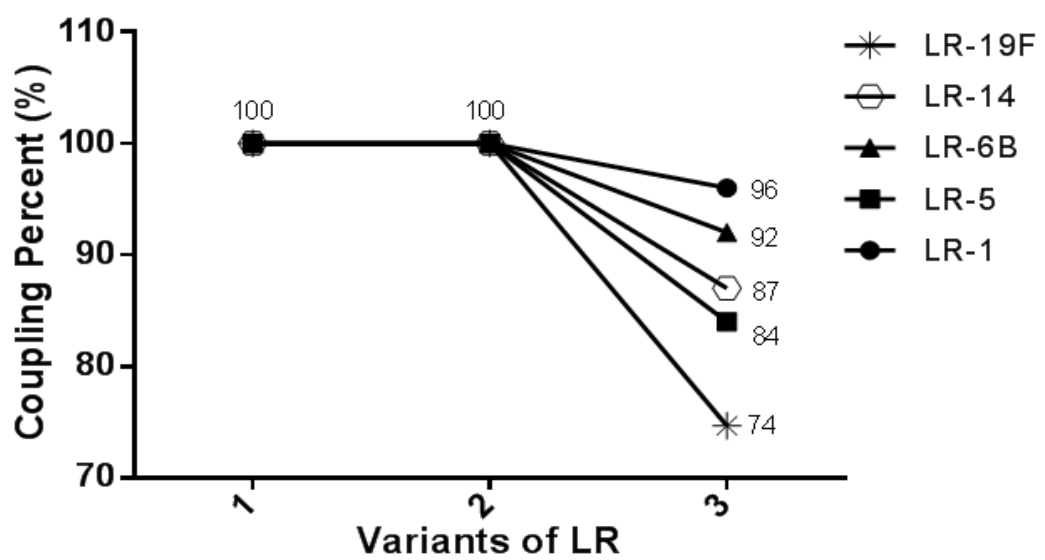

Figure 1: Coupling Percent of the LR variants according to the concentration of the Mab used. Variant $1(100 \mu \mathrm{g} / \mathrm{ml})$, Variant $2(200 \mu \mathrm{g} / \mathrm{ml})$ and Variant $3(500 \mu \mathrm{g} / \mathrm{ml})$. The methodology used for coupling was passive adsorption than the recognition region (Fab), so the arrangement adopted by the Ab during coupling is a deciding factor. If the $\mathrm{Ab}$ is coupled by its $\mathrm{Fc}$ portion, a more biologically active orientation is ensured. However, it is possible that the Ab may be linked in a less optimal manner (by the Fab region). Many authors suggest that this can be avoided by adding an excess of ligand to ensure complete adsorption in an upright position. $[19,20,21]$

On the other hand, the hyphrofobicity of an $\mathrm{Ab}$ also intervenes in the coupling capacity and is related to its amino acid composition. The Abs between them may have Fc regions with different degrees of hydrophobicity, depending on the amount and nature of the amino acid residues that compose it. For example, a polar amino acids such as phenylalanine, tryptophan, alanine, valine, leucine and isoleucine favor hydrophobic interactions, whereas polar amino acids such as arginine, lysine, aspartate and glutamate do not favor it. [19, 21] Any of these factors could explain why starting at $200 \mu \mathrm{g} / \mathrm{ml}$ we begin to see differences in the percent of coupling between MAbs.

Once the LR variants were obtained and their coupling percent known, their functionality was evaluated by agglutination test. This assay is based on an agglutination reaction occurring between the MAbs coupled to the LRs and the PsCs employed. For this assay the PsC were used at $4.4 \mu \mathrm{g} / \mathrm{ml}$, concentration to which they are in Quimi-Vio vaccine. (Table I)

\begin{tabular}{|c|c|c|c|c|c|c|c|}
\hline $\begin{array}{c}\text { Latex } \\
\text { Reagent }\end{array}$ & $\begin{array}{c}\text { Variants } \\
(\mu \mathrm{g} / \mathrm{ml})\end{array}$ & СР(\%) & PsC-1 & PsC-5 & PsC-6B & PsC-14 & PsC-19F \\
\hline \multirow{3}{*}{ RL-1 } & 100 & 100 & + & & & & \\
\hline & 200 & 100 & +++ & & & & \\
\hline & 500 & 96 & ++ & & & & \\
\hline \multirow{3}{*}{ RL-5 } & 100 & 100 & & + & & & \\
\hline & 200 & 100 & & +++ & & & \\
\hline & 500 & 92 & & + & & & \\
\hline \multirow{3}{*}{ RL-6B } & 100 & 100 & & & ++ & & \\
\hline & 200 & 100 & & & +++ & & \\
\hline & 500 & 87 & & & +++ & & \\
\hline \multirow{3}{*}{ RL-14 } & 100 & 100 & & & & + & \\
\hline & 200 & 100 & & & & +++ & \\
\hline & 500 & 84 & & & & ++ & \\
\hline \multirow{3}{*}{ RL-19F } & 100 & 100 & & & & & ++ \\
\hline & 200 & 100 & & & & & +++ \\
\hline & 500 & 74 & & & & & + \\
\hline
\end{tabular}

As can be seen in Table I, all variants of LR for all serotypes showed agglutination reaction. However, the agglutination reactions with the highest degree of positivity (three crosses) occurred with the variants number two (200 $\mu \mathrm{g} / \mathrm{ml}$ ) for all serotypes. Therefore, this concentration was chosen as optimum for the coupling because it presented $100 \%$ of coupling for all MAbs and a clumping of three crosses against the homologous PsC.

In table 1 , is also observed that variants of $100 \mu \mathrm{g} / \mathrm{ml}$, despite having a $100 \%$ coupling, showed agglutination reactions of one or two crosses. This result agrees with what has been expressed by several authors, who state that latex Immunoagglutination is an antigen-antibody reaction in which achieving equilibrium between both molecules is important and decisive for the applicability of the lr obtained. [19, 20, 21]

The existence of recognition of Psc by the homologous Mab after coupled to latex particles Indicates That: 1) The passive adsorption coupling method was effective, 2) The Mab-Particle coupling occurred mainly by the Fc portion 
of the Mab, leaving the Fab region (of recognition) with a biologically active orientation and 3) There was not conformational loss in the Mab, which would irreversiblyaffect the paratopes. Precisely these are the advantages of this method of coupling, Its simplicity, flexibility and the low Probability of producing irreversible modifications in the molecule, which make it A Widely used method

The specificity against each PsC and against each Spn strain was evaluated for the selected LR variant $(200 \mu \mathrm{g} / \mathrm{ml})$ for each serotype (Figure 2 and 3).

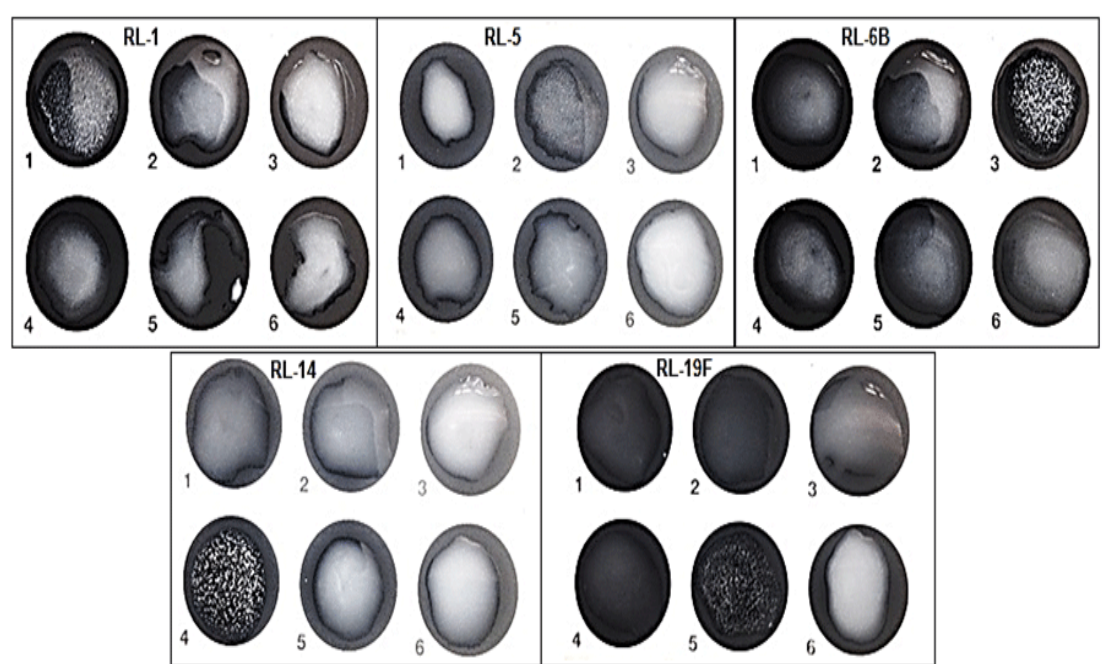

Figure 2: Specificity of Latex Reagents vs. PsC. Each card represents an LR. Each one was challenged with the PsC (1-PsC1, 2-PsC5, 3-PsC6B, 4-PsC14, 5-PsC19F and 6-PBS).

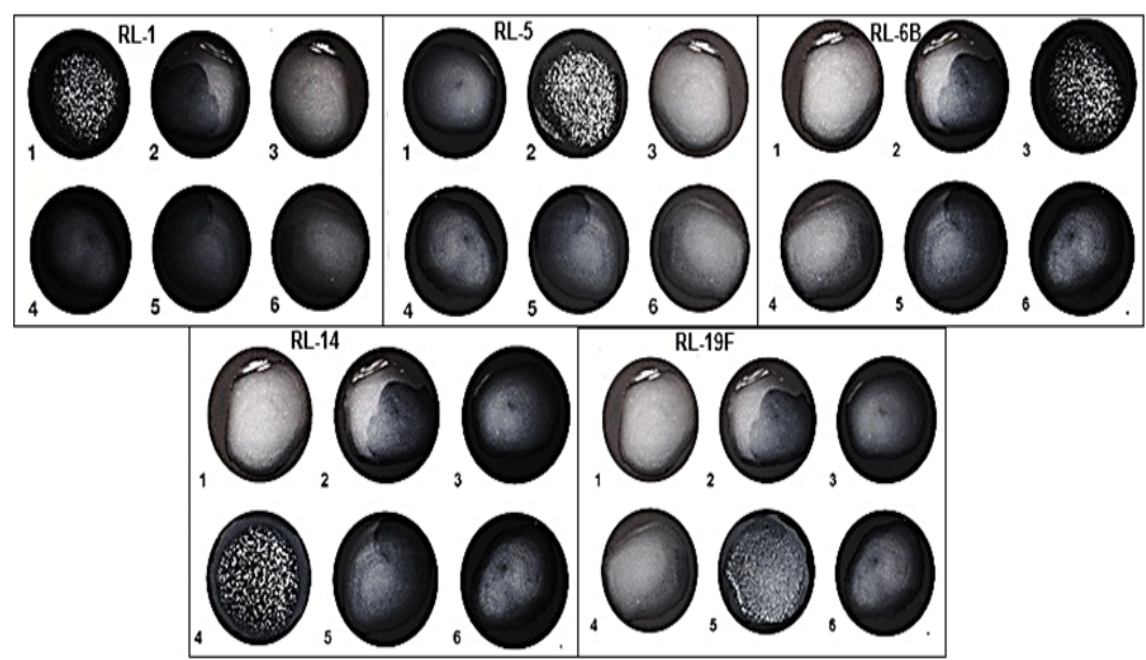

Figure 3: Specificity of Latex Reagents against S. pneumoniae strains. Each card represented one LR Each one was challenged with the strains (1-722, 2-2471, 3-285, 4-989, 5-297 and 6-PBS).

As can be seen in (Figures 2 and 3), only agglutination reaction is observed in the well where the homologous PsC or strain was applied. No cross-reactivity was found between the serotypes evaluated, evidencing the high specificity of the Mabs used to obtain the RLs (15). These results are summarized in Table II and are very important because Quimi-Vio as we have said before is a multivalent vaccine in which all $\mathrm{PsC}$ are together in the same vaccination formulation. So if the objective of obtaining these LR is to guarantee the identity test of this vaccine, knowing that each LR is able to recognize only its homologous PsC in a specific way, suggest that the RLs obtained can be used for the Quimi-Vio identity test by Immunoagglutination

The results obtained with the Immunoagglutination of Spn strains suggest that the LRs can be used in the serotyping of pneumococcal strains too. If we consider that the Quimi-Vio vaccine is in Phase II of the Clinical Trial, this application is very important, because in the field study of the vaccine, these LR could be used for rapid serotyping of nasopharyngeal exudate samples.

Finally, the sensibility of LR coupled to each monoclonal antibody was evaluated with different concentrations of the PsC, ranging from $1000 \mu \mathrm{g} / \mathrm{mL}$ to $1 \mathrm{ng} / \mathrm{mL}$. Table III shows that all LR were reactive at concentrations of the specific
PsC, between $10 \mu \mathrm{g} / \mathrm{mL}$ to $100 \mathrm{ng} / \mathrm{mL}$. This range includes the conjugated QuimiVio vaccine dose of $4 \mu \mathrm{g} / \mathrm{mL}$ per PsC 1, 5, 14, 19F or $8 \mu \mathrm{g} / \mathrm{mL}$ in the case of PsC 6B. Even so, several LR have wider limits of detection with upper limits in $1000 \mu \mathrm{g} /$ $\mathrm{mL}$ and lower limits in $1 \mathrm{ng} / \mathrm{ml}$. The difference in the sensibility of the LR may be related with the differences of avidity of each antibodies and the strength of the coupling with the latex particle.

Table 2: Specificity of LR vs PsC and Spn strains

\begin{tabular}{|c|c|c|c|c|c|c|c|c|c|c|}
\hline Látex & \multicolumn{9}{|c|}{ PsC (serotype) } & \multicolumn{7}{|c|}{ S. pneumoniae strains } \\
\hline Reagent & $\mathbf{1}$ & $\mathbf{5}$ & $\mathbf{6 B}$ & $\mathbf{1 4}$ & $\mathbf{1 9 F}$ & $\mathbf{7 2 2}$ & $\mathbf{2 4 7 1}$ & $\mathbf{2 8 5}$ & $\mathbf{9 8 9}$ & $\mathbf{2 9 7}$ \\
\hline RL-1 & + & - & - & - & - & + & - & - & - & - \\
\hline RL-5 & - & + & - & - & - & - & + & - & - & - \\
\hline RL-6B & - & - & + & - & - & - & - & + & - & - \\
\hline RL-14 & - & - & - & + & - & - & - & - & + & - \\
\hline RL-19F & - & - & - & - & + & - & - & - & - & + \\
\hline
\end{tabular}

Table 3: Sensibility of LR to specific PsC from Spn

Range of concentrations for each PsC $(1,5,6 B, 14,19 F)$ tested vs. LR

$1000 \mu \mathrm{g} / \mathrm{ml} 100 \mu \mathrm{g} / \mathrm{ml} 10 \mu \mathrm{g} / \mathrm{ml} 1000 \mathrm{ng} / \mathrm{ml} 100 \mathrm{ng} / \mathrm{ml} 10 \mathrm{ng} / \mathrm{ml} 1 \mathrm{ng} / \mathrm{ml}$

\begin{tabular}{|c|c|c|c|c|c|c|c|}
\hline AcM aPs1 & ++ & +++ & +++ & +++ & +++ & - & - \\
\hline AcM aPs5 & - & - & ++ & +++ & +++ & +++ & ++ \\
\hline AcM aPs6B & +++ & +++ & +++ & +++ & +++ & - & - \\
\hline \begin{tabular}{c|c|c|c|c|c|c|c|} 
AcM aPs14 \\
AcM
\end{tabular} & +++ & +++ & +++ & +++ & +++ & +++ & +++ \\
\hline \begin{tabular}{c} 
aPs19F \\
\hline
\end{tabular} & +++ & +++ & +++ & +++ & +++ & - & - \\
\hline
\end{tabular}

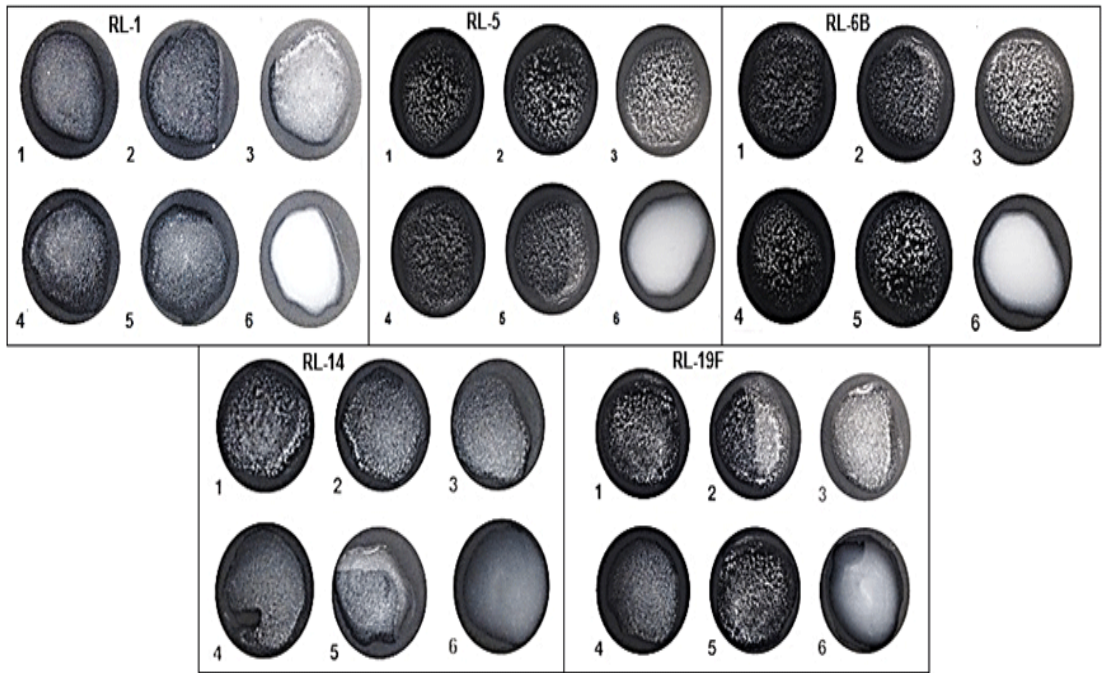

Figure 4: SIdentification of PsC 1, 5,6B, 14 and 19F in the Quimi-Vio vaccine, by immunoalgutination using the obtained LR. Each card represents an RL. Three batches of Quimi-Vio (NEU.15.01-wells 1, NEU.15.02-wells 2 and NEU.16.02-wells 3) and one batch of the commercial Prevenar 13 vaccine (wells 4 ) were evaluated. As positive and negative controls was used the PsC homologous (wells 5) and PBS (wells 6) respectively. 


\section{Identity test of Quimi-Vio vaccine}

Three batches of Quimi-Vio, one batch of Prevenar 13 were evaluated and the different PsC were used as positive control (Figure 4).

Figure 4 show the specific recognition of each PsC in Quimi-Vio vaccine for each LR. These results allow to affirm that the obtained LR can be used to identify each PsC in the vaccine (identity test). These results have a high importance because Quimi-Vio is a vaccine that is in a clinical trial, so it takes this stage, the analytical tool that guarantees the tests for product characterization and quality control is without a doubt a great tool.

Vaccine Identity Test are qualitative rather than quantitative methods and have been classified by several authors as physical-chemical methods, immunological methods and combinations between them. [8, 18, 22]Among the first are: nuclear magnetic resonance (NMR), reverse phase chromatography, twodimensional electrophoresis (isoelectric focusing followed by SDS-PAGE) and mass spectrometry, etc. Is true that many of these methods have revolutionized identity testing from the technological point of view, they have the disadvantages of being very expensive, not being available to all laboratories, they need a highly qualified staff and in most of the cases require prior treatment of the sample. [8, $9,10]$

Immunoassays are based on the Antigen-Antibody reaction. In immunoagglutination techniques, this Ag-Ac reaction becomes visible (agglutination) because one of the two molecules are forming part of or artificially joined to particulate systems such as the surface of red blood cells, platelets, leukocytes, or latex particles, etc. Agglutination using latex particles is very useful because it is a very fast technique, easy to use, and when high specificity and affinity MAbs are used, their value as analytical technique increases. Marrero et al 2017 demonstrate the stability of latex particles used to develop the prototype of LR evaluated in this work [23] and further studies will be carried out to demonstrate the stability of the latex-Mab complex. However, the results of this work demonstrate that variants of LR selected for the experiments showed high coupling percentage (Figure 1), also the suspensions remained smooth and white after the coupling and neither auto-agglutination or agglutination was observed using saline solutions.

Dot Blottechnique has been used for the identity test of several vaccines in our Institute, for example to identify the Neisseria meningitidis PsC serogroup C present in the Cuban meningococcal vaccine VAMENGOC-BC, where Biomérieux and Remel latex reagents from France and UK respectively are used. [24]

Likewise, these results demonstrate that RLs can also be used to identify the different SpC PsCs throughout the production process of the vaccine (identification of strains, the active ingredient after purification and the active ingredient in bulks or final formulation). All controls are carried out at the Finlay Institute in accordance with WHO recommendations and are intended to ensure the correspondence between the active component stated on the packaging labe and that present in the vaccine preparation obtained. For this reason, these tests constitute one of the main requirements for the release, administration and subsequent commercialization of the product. on the other hand, its use would not be conditional on the purchase in the market of reagents that guarantee it so it could be more economical to implement its use for this test in the release of lots of vaccines.

\section{Conclusion}

Latex reagents based on MAbs against the PsC serotypes 1, 5,6B, 14 and $19 \mathrm{~F}$ of Spn, coupled to latex particles were obtained. The best variant of these latex reagents obtained was the one that used $200 \mu \mathrm{g} / \mathrm{mLof}$ MAb for coupling, to all serotypes. With this variant of latex reagent, each PsC present in the three batches of Quimi-Vio vaccine was specifically identified. Taking into account that the vaccine identity test is a mandatory requirement for the final release of lots, ensuring the reagents necessary for its realization both in quantity and quality is of great importance. On the other hand, having a battery of MAbs with high specificity, reproducibility and in house production is a great achievement. These MAbs may be used for other purposes than identity testing alone.
Vaccine Identity Test are qualitative rather than quantitative methods and have been classified by several authors as physical-chemical methods, immunological methods and combinations between them. [8, 18, 22]Among the first are: nuclear magnetic resonance (NMR), reverse phase chromatography, twodimensional electrophoresis (isoelectric focusing followed by SDS-PAGE) and mass spectrometry, etc. Is true that many of these methods have revolutionized identity testing from the technological point of view, they have the disadvantages of being very expensive, not being available to all laboratories, they need a highly qualified staff and in most of the cases require prior treatment of the sample. [8, $9,10]$

Immunoassays are based on the Antigen-Antibody reaction. In immunoagglutination techniques, this Ag-Ac reaction becomes visible (agglutination) because one of the two molecules are forming part of or artificially joined to particulate systems such as the surface of red blood cells, platelets,

\section{References}

1. Skinner JM, Indrawati L, Cannon J, Blue J, Winters M, Macnair J, et al. Pre-clinical evaluation of 15-valent pneumococcal conjugate vaccine (PCV15-CRM197) in an infant-rhesus monkey immunogenicity model. Vaccine. 2011. Nov 8;29(48):8870-6. doi: 10.1016/j.vaccine.2011.09.078.

2. O’Brien KL, Wolfson LJ, Watt JP, Henkle E, Deloria-knoll M, McCall N, et.al. Burden of disease caused by Streptococcus pneumoniae in children younger than 5 years: global estimates. Lancet. 2009. Sep 12; 374(9693):893-902. doi: 10.1016/S01406736(09)61204-6.

3. Fedson DS, Nicolas-Spony L, Klemets P, van der Linden M,Marques A,Salleras L,et. al.Pneumococcal polysaccharide vaccination for adults: new perspectives for Europe. Expert Rev Vaccines. 2011. Aug;10(8):1143-67. doi: 10.1586/erv.11.99.

4. Simell B, Auranen K, Käyhty H ,Goldblatt D, Dagar R,O’Brien KL ,The fundamental link between pneumococcal carriage and disease. Expert Rev Vaccines. 2012. Jul; 11(7):84155. doi: 10.1586/erv.12.53

5. Toraño GT, Llanes R, Pías LM, Miriam Abreu Capote, Marlein Valcarcel Sanchez, Serotipos de Streptococcus pneumoniae en Cuba y progresión de la resistencia a la penicilina. Revista Cubana de Medicina Tropical. 2010; 62(2):157-60.

6. Toraño GT, Pías LM, Abreu M, y col. Serotipos y resistencia antimicrobiana de aislamientos meníngeos de Streptococcus pneumoniae. Cuba, 2007-2012. Vacci Monitor 2014;23(3):117-123.

7. WHO Expert Committee on Biological Standardization. Recommendations to Assure the Quality, Safety, and Efficacy of Pneumococcal Conjugate Vaccines. WHO Technical Report Series, No. 977, 2013, Annex 3.

8. Metz B, van den Dobbelsteen G, van Els C ,van der Gun J, Levels, van der Pol L ,et .al Quality-control issues and approaches in vaccine development. Expert Rev Vaccines. 2009. Feb; 8(2):227-38. doi: 10.1586/14760584.8.2.227.

9. Hamm M, Ha Sha and Rustand R. Automated capillary Western dot blot method for the identity of a 15-valent pneumococcal conjugate vaccine, Anal. Biochem. 2015. June: 478.33-39. doi: 10.1016/j.ab.2015.03.021.

10.Abeygunawardana C, Williams TC, Sumner JS, Hennessey JP Jr. Development and validation of an NMR-based identity assay for bacterial polysaccharide. Anal Biochem. 2000. Mar 15 ;279(2):226-40. doi:10.1006/abio.1999.4470

11.Molina J.A. and Galisteo F. Latex Immunoagglutination Assays. Journal of Macromolecular Sciencew. 2005: Part C-Polymer Reviews 45: 59-98.

12.González E, Otero 0, Amin N ,Fidel , Maribel Cuello and Fatim. purificación y caracterización del AcM contra polisacárido capsular Vi de Salmonella Typhi y su aplicabilidad en ensayos de identidad. Revista Bioprocesos, 2015;1(3):1-12.

13.Reyes F, Otero 0, Cuello M, Amin N ,Garcia L ,Cardoso D,et.al. Development of four sandwich ELISAs for quantitation of capsular polysaccharides from Neisseria meningitidis serogroups A, C, W and Y in multivalent vaccines. J Immunol Methods. 2014. May; 407:58-62. doi: 10.1016/j.jim.2014.03.020. Epub 2014 Apr 12.

14.Saydam, M., Rigsby, P. and Mawas, F. A novel Enzyme-Linked Immuno-Sorbent Assay (ELISA) for the quantification of total and free polysaccharide in Haemophilus influenzae b-Tetanus toxoid conjugate vaccines in monovalent and combined vaccine formulations. Biologicals. 2014. Jan;42(1):29-33. doi: 10.1016/j.biologicals.2013.10.002. Epub 2013 Nov 5. 
15.Ramírez F, Fajardo A, González E y col. Obtaining and characterization of five monoclonal antibodies specific to capsular polysaccharide of Streptococcus pneumoniae serotype 1, 5, 6B and 14. Revista Bionatura. 2017.

16.Dellepiane N, GriffithsE. y Milstien JB. Nuevos retos para asegurar la calidad de las vacunas.Boletín de la Organización Mundial de la Salud. 2000, 78 (3): 43-50

17.Cunningham AL, Garçon N, Leo O, Friedland LR, Strugnell R, Laupèze B, et al. Vaccine development: From concept to early clinical testing. Vaccine 2016; 34:6655-64. Doi:10.1016/j.vaccine.2016.10.016.
18.Hendriksen C, Arciniega JL, Bruckner L and M Chevalier .The consistency approach for the quality control of vaccines. Biologicals. 2008,36:73-77. Doi:10.1016/j. biologicals.2007.05.002

19.Comesaña, Y. Estudio de la adsorción de inmunoglobulina Y sobre partículas de poliestireno (Tesis de Diploma). Universidad de La Habana, Ciudad de La Habana. (2005)

20.Bangs Laboratories, Inc. Adsorption to Microspheres. TechNote 204 Rev. \#003, Active: 2013 